\title{
Decolorization and Biodegradation of basic violet dye by fungal- bacterial consortia
}

\author{
D.R. Manimaran \\ Department of Biotechnology, Kumaraguru College of Technology, Coimbatore -49 \\ manimaran.dr.bt@kct.ac.in \\ P. Ramalingam \\ Department of Biotechnology, Kumaraguru College of Technology Coimbatore-49 \\ ramalingam.p.bt@kct.ac.in
}

\section{ABSTRACT}

The present study was aimed to test the ability of Penicillium citrinum MTCC 8009, Aspergillus terreus MTCC 3006, Bacillus cohnii and their consortia to decolorize basic violet dye. Different parameters such as initial dye concentration, dye to inoculum ratio and period of incubation were studied for the decolourization of the dye. The developed fungal- bacterial consortia exhibited maximum percent decolorization (92\%) ability when compared to the treatment of dyes by individual microbes. Percent decolorization of basic violet dye (92\%) was more efficient using fungal-bacterial (Penicillium citrinum and Bacillus cohnii) consortia than with individual cultures. Phyto-toxicity results indicated that bacterial-fungal consortia (Penicillium citrinum and Bacillus cohnii) treatment was believed to degrade the dyes to non-toxic intermediates. The FTIR analysis also revealed that decolorization of basic violet dyes was due to its degradation.

\section{Indexing terms/Keywords}

Basic violet dye, microbial remediation, fungal bacterial consortia, phyto-toxicity, FTIR.

\section{INTRODUCTION}

Dyes are coloured substances, which are used along with a mordant to impart colour to fibres. There are about 10,000 different dyes that are used globally [18]. The textile industry releases about $10 \%$ of the above-mentioned value as their effluents in fresh water which was toxic to the environment [15]. The dyes from textile dyeing effluents pose a serious threat to environment even at a very low concentration $(1 \mathrm{mg} / \mathrm{L})$. So, these effluents must be treated before they reach the environment [27]. Various treatment technologies have been investigated extensively such as the photochemical oxidation [20], membrane [28], chemical coagulation [1,24], adsorption [13,16,19] aerobic and anaerobic biological processes [11,14], nano filtration [8,26], electrocoagulation, ultra-sonic decomposition [3], pre-dispersed solvent extraction [10], ozonation $[4,22]$, colloidal gas aphrons [21] and liquid- liquid extraction [6,12]. Although the aforesaid physico-chemical methods are economical, they generate sludge which are difficult to dispose-off and these sludges are secondary pollutants. There are viable technologies to treat the sludge. Biological treatments are being extensively investigated due to their low cost and efficient degradation process. Adsorption is one such biological method in which the microbial cells take-up the dyes on their external cell surface, and further they absorb the dyes into the cell. After this, biotransformation of the dye which involves enzymatic degradation takes place and as a result of this process the dye loses its toxicity. Several microorganisms belonging to different taxonomic groups like bacteria, fungi, yeast, algae, actinomycetes etc. have shown their capability to degrade dyes. Despite their great promise, both the bacteria and fungi have faced lot of challenges with respect to their ability to decolourise the dyes individually. On the other hand, some of them have resulted in the release of carcinogenic and mutagenic metabolites. The use of fungi in bioremediation of textile effluent was limited because of their slow growth rate and greater hydraulic retention time to decolorize the dyes completely.

An enhanced degradation and detoxification of the textile dyes could be possible with the synergetic actions of fungi and bacteria consortia which provide a better alternative technology for the removal of pollutants in the water [7,17,23]. In addition, rapid rates of decolorization proved that these synergetic consortia might be a powerful weapon to attack the dyes and completely mineralise them into non-toxic substances. Fungi despite of its slower growth rate is known to secrete various extra cellular enzymes like manganese peroxidase, lignin peroxidase and laccase which are non-specific to the dye molecules. These enzymes upon acting on the dye deforms the dye structure thereby reducing its toxicity. Thus, the fungalbacteria consortia coordination could be an additional advantage as they have inductive effects on various enzymes which could have improved action than in individual system. Fungal-bacterial consortia system could be further exploited in depth for the eco-friendly remediation of the textile effluents.

\section{MATERIALS AND METHODS}

\subsection{Chemicals}

Veratryl alcohol, methyl red, ABTS, Nutrient Medium (NM), toluene, ethyl acetate, methanol and potato dextrose broth (PDB) were obtained from HiMedia Laboratories Pvt. Ltd., Mumbai. Basic violet dye was obtained from TIFAC-CORE department, Kumara guru College of Technology, Coimbatore. All chemicals used were of highest purity available and of an analytical grade. UV-Visible Spectrophotometer (Shimadzu, UV-1800) was used for measuring the absorbance of the solutions. 


\subsection{Microorganism and media}

Penicillium citrine MTCC 8009 and Aspergillus terreus MTCC 3006 were procured from Microbial Type Culture Collection (MTCC), Institute of Microbial Technology (IMTECH), Chandigarh. Fungal cultures were periodically subcultured on Czapek-Dox agar slants and are stored at $4^{\circ} \mathrm{C}$. B.cohnii was obtained from Bioprocess Lab, KCT and was maintained on nutrient agar slants at $4^{\circ} \mathrm{C}$. The composition of potato dextrose broth [PDB] used for decolourization studies was $(\mathrm{g} / \mathrm{l})$ : potatoes infusion 200 , dextrose 20 and yeast extract 5 .

\subsection{Degradation of dyes by microbial consortia}

The fungal cultures from the stock were inoculated into $250 \mathrm{ml}$ of Erlenmeyer flasks containing $100 \mathrm{ml}$ of PDB and incubated for 8 days at $30^{\circ} \mathrm{C}$ under shaking condition. One loopful of $24 \mathrm{~h}$ old grown Bacillus cohnii was inoculated into $100 \mathrm{ml}$ of nutrient broth [NB] and incubated at $37^{\circ} \mathrm{C}$ for $24 \mathrm{~h}$ under shaking condition. Penicillium citrinum and Bacillus cohnii consortia was prepared aseptically by transferring the $50 \mathrm{ml}$ of 8 days grown Penicillium citrinum into 250 $\mathrm{ml}$

Erlenmeyer flasks containing $50 \mathrm{ml}$ of log phase cells of Bacillus cohnii. Similar method was followed for consortia PA (Penicillium citrinum and Aspergillus terreus consortia) and consortia AB (Aspergillus terreus and Bacillus cohnii consortia). The pre-grown individual cultures and its developed consortia were then used as inoculums for further degradation studies. The dyes were subjected to degradation studies considering different parameters such as initial dye concentration, dye to inoculum ratio and the period of incubation.

\subsection{Decolorization experiment}

Decolorization of basic violet dye was carried out under shaking condition with $100 \mathrm{ml}$ of PDB containing Aspergillus terreus and Penicillium citrinum in PDB, and Bacillus cohnii in NB. Initial dye concentrations used in the investigation were $20,40,60$, and $100 \mathrm{mg} / \mathrm{l}$ of dye. A condition of $50 \%$ dye to inoculum ratio was prepared by aseptically transferring equal volumes of dye and inoculum. Similarly, for $75 \%$, it was $37.5 \mathrm{ml}$ of dye and $13.5 \mathrm{ml}$ of inoculum or the developed consortia.

Dye to inoculum ratio (100\%) was also prepared aseptically by transferring the loopful of culture or its developed consortia into the prepared dye solution. Aliquots of the cultured supernatant were withdrawn at regular intervals of time and $\%$ decolorization were calculated.

\section{$\%$ decolorization $=$ Initial absorbance - Observed absorbance $\times 100$ \\ Initial absorbance}

\subsection{Enzyme assay}

The ligninolytic enzymes such as lignin peroxidase [25], laccase [2] and manganese peroxidase [9] were determined as reported in the literature.

\subsection{Metabolite analysis}

After decolorization of basic violet dye, the fungal mycelia were removed by filtration through Whatman filter paper no. 1 while bacterial cells were removed by centrifugation at $10,000 \mathrm{rpm}$ for $20 \mathrm{~min}$. Similarly, the Penicillium citrinum-Bacillus cohnii consortium biomass were removed by filtration using mesh cloth followed by centrifugation of the filtrate at 10,000 rpm for 20 min. The supernatant thus obtainedwas subjected to TLC and FTIR analysis.

\subsection{UV-Visible analysis of degraded products of basic violet dye}

The maximum wavelength of the authentic and its degraded products were checked using UV-Visible spectrophotometer. UV-Visible spectra of authentic dye were compared with original dye to find the extent of degradation process.

\subsection{FTIR analysis}

FTIR analysis was performed in order to investigate the changes in surface functional groups of the degraded dye products before and after microbial treatment. FTIR analysis was done using Shimadzu spectrophotometer.

\subsection{Toxicity studies}

To determine the toxicity of the degraded samples, phyto-toxicity test was carried out on Vigna radiata. Ten healthy seeds of Vigna radiata were separately sowed into plastic pots containing $20 \mathrm{~g}$ of washed and oven dried sand. The toxicity study was carried out at room temperature $27^{\circ} \mathrm{C}$ by daily watering $5 \mathrm{ml}$ of degraded dye solution. Simultaneously, control set was carried out at the same time by daily watering it with the dye solution that was not treated. Tests were done and the results are presented as an average.

Germination $(\%)=($ No of seeds germinated $/$ No. of seeds sowed $) * 100$

\section{RESULTS AND DISCUSSION}


Table 1: \% dye decolorization of dye $(20 \mathrm{mg} / \mathrm{l})$ at different time intervals

\begin{tabular}{|c|c|c|c|c|c|c|c|c|c|c|}
\hline & \multirow{2}{*}{$\begin{array}{l}\text { No. of days } \\
\begin{array}{c}\text { Dye to inoculum } \\
\text { ratio (\%) }\end{array}\end{array}$} & \multicolumn{3}{|c|}{ Day 2} & \multicolumn{3}{|c|}{ Day 6} & \multicolumn{3}{|c|}{ Day 10} \\
\hline & & 50 & 75 & 100 & 50 & 75 & 100 & 50 & 75 & 100 \\
\hline \multirow{6}{*}{ 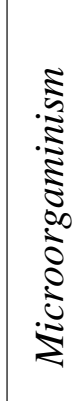 } & P.citrinum & 38 & 26 & 7 & 56 & 42 & 36 & 72 & 62 & 60 \\
\hline & A.terreus & 33 & 30 & 22 & 42 & 32 & 27 & 56 & 41 & 40 \\
\hline & B.cohnii & 17 & 20 & 16 & 37 & 26 & 23 & 52 & 36 & 32 \\
\hline & $B+P$ & 56 & 48 & 38 & 82 & 63 & 58 & 84 & 82 & 80 \\
\hline & $B+A$ & 62 & 42 & 30 & 78 & 59 & 63 & 92 & 84 & 78 \\
\hline & $P+A$ & 48 & 37 & 26 & 68 & 52 & 48 & 86 & 80 & 78 \\
\hline
\end{tabular}

It was evident from Table 1 that on day 2, basic violet dye was degraded to $62 \%$ by Penicillium citrinum and Bacillus cohnii consortia at $50 \%$ dye to inoculums ratio while Bacillus cohnii-Aspergillus terreus decolorized the dyes to $48 \%$ and $38 \%$ at $75 \%$ and $100 \%$ dye to inoculum ratio, respectively. It was clear from Table 1 that on day 6 , Bacillus cohniiAspergillus terreus consortia at $50 \%$ and $75 \%$ dye to inoculums ratio degraded the basic dye to $82 \%$ and $63 \%$, respectively, while Penicillium citrinum and Bacillus cohnii consorti decolorized the dyes to $63 \%$. It also apparent from Table 1 that on $10^{\text {th }}$ day, $P$. citrinum and Bacillus cohnii consortia at $50 \%$ and $75 \%$ dye to inoculums ratios degraded the basic dye to $92 \%$ and $84 \%$, respectively. Bacillus cohnii-Aspergillus terreus consortia decolorized the dyes to maximum $(80 \%)$ at $100 \%$ dye to inoculum's ratio.

Table 2: \% Dye decolourization for $60 \mathrm{mg} / \mathrm{l}$ of initial dye concentration

\begin{tabular}{|c|c|c|c|c|c|c|c|c|c|c|}
\hline & \multirow{2}{*}{\begin{tabular}{|l|} 
No. of days \\
$\begin{array}{c}\text { Dye to inoculum } \\
\text { ratio }(\%)\end{array}$ \\
\end{tabular}} & \multicolumn{3}{|c|}{ Day 2} & \multicolumn{3}{|c|}{ Day 6} & \multicolumn{3}{|c|}{ Day 10} \\
\hline & & 50 & 75 & 100 & 50 & 75 & 100 & 50 & 75 & 100 \\
\hline \multirow{6}{*}{ 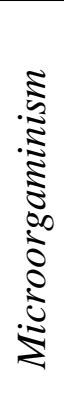 } & P.citrinum & 28 & 26 & 17 & 39 & 34 & 25 & 45 & 43 & 29 \\
\hline & A.terreus & 26 & 20 & 15 & 31 & 28 & 25 & 37 & 39 & 35 \\
\hline & B.cohnii & 10 & 8 & 5 & 22 & 19 & 10 & 30 & 50 & 42 \\
\hline & $B+P$ & 48 & 36 & 30 & 63 & 48 & 41 & 79 & 70 & 49 \\
\hline & $B+A$ & 40 & 52 & 48 & 69 & 59 & 55 & 70 & 62 & 63 \\
\hline & $P+A$ & 32 & 36 & 32 & 53 & 43 & 35 & 61 & 55 & 57 \\
\hline
\end{tabular}

The percentage decolourization of basic violet dye was evident from the Table 2 that on day 2, B. cohnii and A. terreus decolorized the dye to $52 \%$ and $48 \%$ at $75 \%$ and $100 \%$ dye to inoculum ratio whereas $P$. citrinum and $B$. cohnii degraded the basic violet dye to $48 \%$ at $50 \%$ dye to inoculum ratio, respectively. Then on day 6 , it is clear that $B$. cohnii and $A$. terreus decolorized the dye to $69 \%$ and $59 \%$ at $50 \%$ and $75 \%$ dye to inoculum ratio whereas $P$. citrinum and $B$. cohnii removed the basic violet dye to $63 \%$ at $50 \%$ dye to inoculum ratio, respectively. It was apparent from Table 2 that on day

10, B. cohnii and A. Terreus decolourized the dye to $70 \%$ and $62 \%$ at $50 \%$ and $75 \%$ dye to inoculum ratio. Thus, it is clear from the Table 2 data that on day 10, the percentage decolourization was found to be maximum i.e., $79 \%$ when the dyes were treated with Penicillium citrinum and Bacillus cohnii consortia.

Table 3: \% Dye decolourization for $100 \mathrm{mg} / \mathrm{l}$ of initial dye concentration

\begin{tabular}{|c|l|c|c|c|c|c|c|c|c|}
\hline & No. of days & \multicolumn{3}{|c|}{ Day 2 } & \multicolumn{3}{c|}{ Day 6 } & \multicolumn{3}{c|}{ Day 10 } \\
\cline { 2 - 10 } & $\begin{array}{c}\text { Dye to inoculum } \\
\text { ratio (\%) }\end{array}$ & 50 & 75 & 100 & 50 & 75 & 100 & 50 & 75 \\
\hline \multirow{2}{*}{ P.citrinum } & 17 & 15 & 121 & 23 & 22 & 17 & 28 & 24 & 22 \\
\hline
\end{tabular}




\begin{tabular}{|c|c|c|c|c|c|c|c|c|c|c|}
\hline B.cohnii & 5 & 4 & 4 & 10 & 8 & 8 & 14 & 12 & 10 \\
\cline { 2 - 9 } & $B+P$ & 42 & 30 & 20 & 52 & 38 & 28 & 68 & 48 & 38 \\
\cline { 2 - 9 } & $B+A$ & 35 & 42 & 39 & 42 & 42 & 40 & 48 & 46 \\
\cline { 2 - 9 } & 27 & 29 & 26 & 34 & 32 & 30 & 40 & 38 \\
\hline
\end{tabular}

From the Table 3 on day 2 basic violet dye was degraded to $42 \%$ dye by $P$. Citrinum and $B$. cohnii consortia at $50 \%$ dye to inoculums ratio while Bacillus cohnii and Aspergillus terreus decolorized the dyes to $42 \%$ and $39 \%$ at $75 \%$ and $100 \%$ dye to inoculum ratio, respectively. On day 6 , table 3 data showed that Penicillium citrinum and Bacillus cohnii consortia at $50 \%$ dye to inoculum ratio decolourized the dye to $52 \%$ whereas the degradation was achieved only upto $42 \%$ and $40 \%$ by Bacillus cohnii and Aspergillus terreus consortia at $75 \%$ and $100 \%$ dye to inoculum ratio, respectively. It is also evident from the Table 3 that the percent decolourization decreases with an increase in dye concentration in all the days using Penicillium citrinum and Bacillus cohnii consortia. Penicillium citrinum and Bacillus cohnii consortia. showed maximum percent $(68 \%)$ decolorization on $10^{\text {th }}$ day with $50 \%$ dye to inoculum ratio.

\subsection{Enzyme activities}

Fig. 1: The fungal bacterial consortia (Penicillium citrinumand Bacillus cohnii) showed maximum lignin peroxidase activity $(1.8 \mathrm{U} / \mathrm{ml})$ with $20 \mathrm{mg} / \mathrm{l}$ of dye concentration.

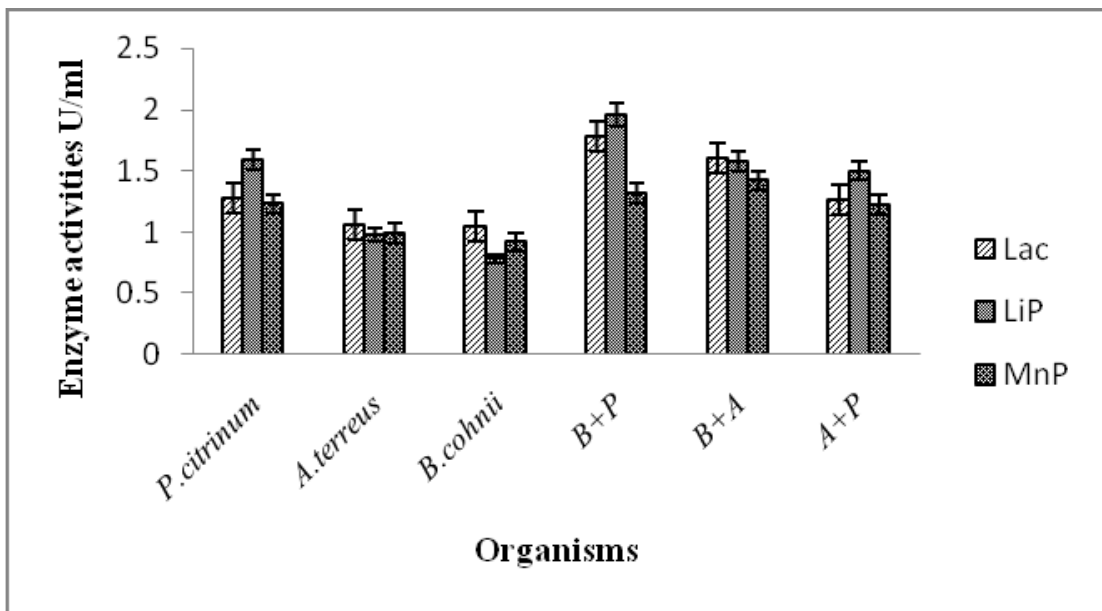

Fig. 2: The fungal bacterial consortia (Penicillium citrinum and Bacillus cohnii) showed lignin peroxidase activity of (2.3 $\mathrm{U} / \mathrm{ml}$ ) with $60 \mathrm{mg} / \mathrm{l}$ of dye

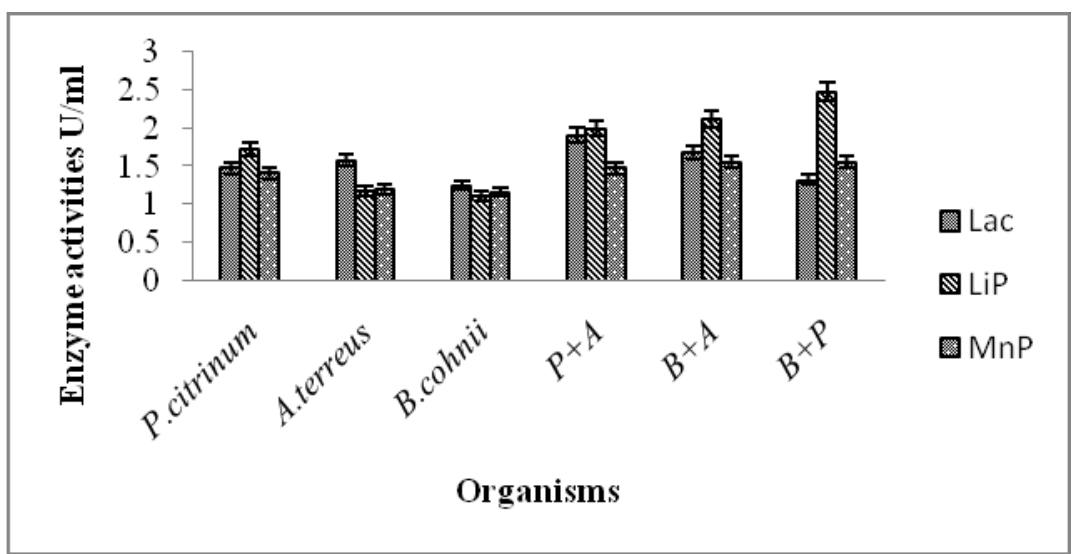
concentration. 
Fig. 3: The fungal bacterial consortia (Penicillium citrinum and Bacillus cohnii) showed lignin peroxidase activity of (2.7 $\mathrm{U} / \mathrm{ml}$ ) with $100 \mathrm{mg} / \mathrm{l}$ of dye concentration.

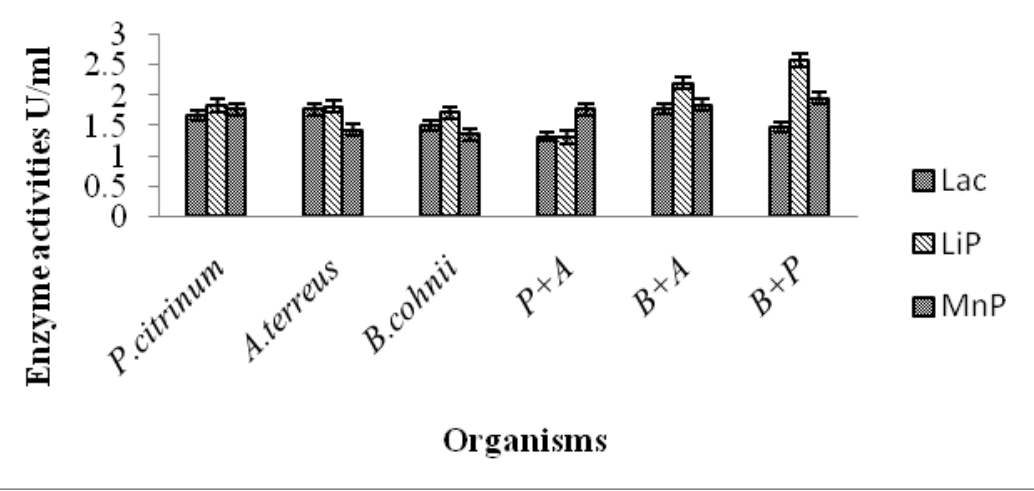

Fig. 4: UV-Visible spectra of basic violet dye and its degraded products.

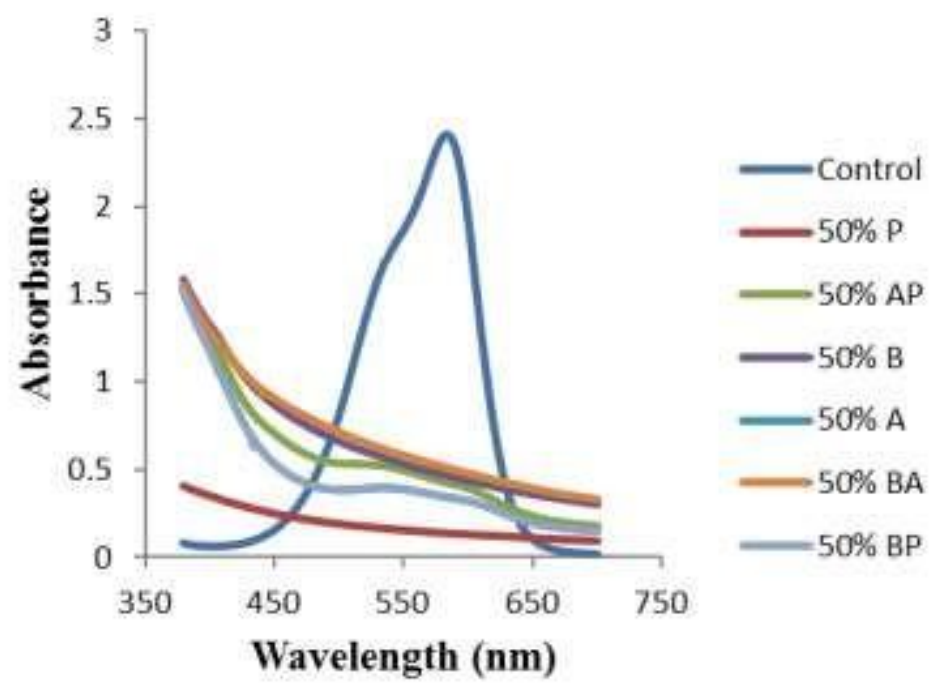

Fig 5 - The FTIR analysis for the dye and its degraded product

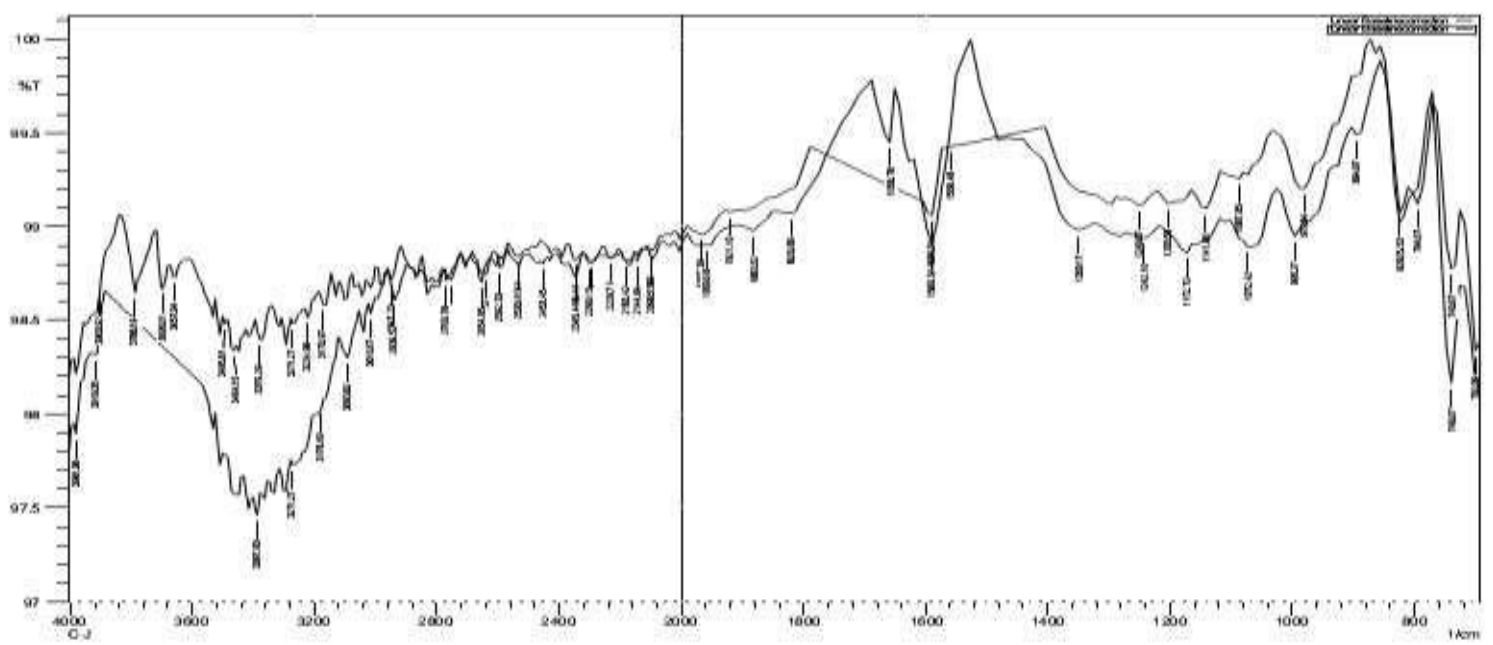

The FTIR spectra for basic violet showed specific peaks at $3464.15 \mathrm{~cm}^{-1}$ (for OH stretching), $1658.78 \mathrm{~cm}^{-1}$ (for $\mathrm{C}=\mathrm{C}$ - stretching of alkenes), $15.89 .34 \mathrm{~cm}^{-1}$ (for $\mathrm{C}-\mathrm{C}$ stretching if aromatic compounds), $1350.17 \mathrm{~cm}^{-1}$ (for $\mathrm{C}-\mathrm{H}$ vibration of alkanes), $995.27 \mathrm{~cm}^{-1}$ (for $=\mathrm{C}-\mathrm{H}$ bending of alkenes), $825.53 \mathrm{~cm}^{-1}$ (for $\mathrm{C}-\mathrm{Cl}$ stretching of alkyl halides), and at $740.67 \mathrm{~cm}^{-1}$ (for the bending of alkynes). After the consortium (B+P) decolorization, a significant reduction in IR peaks was observed in

the $3387 \mathrm{~cm}^{-1}$ (for N-H stretching of primary and secondary amines), 1589.34 (for C-C stretching of aromatic compounds), $1141.86 \mathrm{~cm}^{-1}$ (for C-N) and at $740.67 \mathrm{~cm}^{-1}$ (for the C-Cl alkyl halide stretching). Vanishing of major peaks and formation of new peaks in the FTIR spectrum of metabolites released by Penicillium citrinum-Bacillus cohnii consortia suggests the

6442 | P a g e 
biotransformation of basic violet dye into distinct non-toxic metabolites. These results also indicated that decolorization of the dye was by virtue of biodegradation.

\subsection{PHYTO-TOXICITY STUDIES}

Fig.6-Germination of Vigna radiata seedling on Penicillium citrinum-Bacillus cohnii treated dye solution

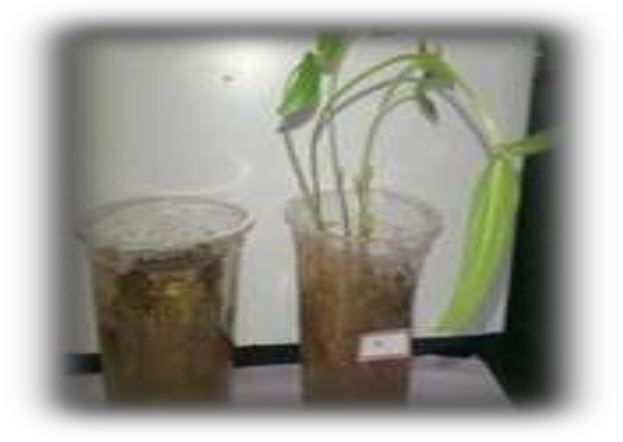

Basic violet dye $(100 \mathrm{mg} / \mathrm{l})$ strongly inhibited the germination of Vigna radiata. On the contrary, degraded products of the dye did not inhibit the germination of the seedlings (Fig.7). Complete germination (100\%) as well as significant growth in the plumule and radicals were observed for the plants grown in (Penicillium citrinum-Bacillus cohnii) a treated dye consortium metabolites as compared to authentic dye. Results of the present investigation indicates that the dye was toxic to these plants, while the metabolites formed after consortium degradation was less toxic, which signifies the detoxification of dye by Penicillium citrinum-Bacillus cohnii consortium. These results also underline the importance of fungal-bacterium synergism for bioremediation of textile effluent in terms of both decolorization and detoxification. Plant bioassays have been used to establish the toxicity levels of dye, and its degraded products on common agricultural crops. The assessment of toxicity of dyes, and its degraded products is often great concern as most of them exert toxic effect on plants and animals when released in stream water. Rubine GFL dye was decolorized to $78 \%$ using fungal-bacteria consortia of Pseudomonas sp. and Aspergillus ochraceus [5].They also reported that dye degrading enzymes such as azoreductase, veratyl oxidase, tyrosinase, laccase, and NADH-DCIP reductase enzymes in the medium were responsible for the decolorization of Rubine GFL dye. In the present study, microbial consortia consisting of Penicillium citrinum and Bacillus cohnii showed maximum percent $(92 \%)$ decolorization for basic violet dye. Ligniniolytic enzymes such as lignin peroxidase, laccase and manganese peroxidase were detected in the medium and these enzymes were believed to be responsible for the degradation of basic violet dye. Further, FTIR analysis for the dye and its degraded product showed the disappearance of major peaks at their functional group and a similar results reported in the literature [5]. Results of phytotoxicity of the present study are in good agreement with their work using fungal-bacterial consortia.

\section{CONCLUSION}

Fungal-bacterial synergetic consortium was applied for the degradation of basic violet dye in submerged conditions. Results revealed that the synergetic metabolic activities of Bacillus cohnii and Penicillium citrinum the consortium led to complete decolorization of basic violet dye. An enhanced efficiency of Penicillium citrinum-Bacillus cohnii consortia could be due to constitutive levels of ligninolytic enzymes (laccase, lignin peroxidase and manganese peroxidase). Results of the present investigation paves the way for the decolorization of dye with co-culture approach that could alleviate the pollution problems due to synthetic dyes. Thus in this present work the degradation was found to be more efficient i.e., 92 $\%$ of degradation in fungal bacterial (Penicillium citrinum and B. cohnii) consortia at the day 10 for $50 \%$ of dye to inoculum ratio when compared with the individual cultures. An increase in the concentration of dye increases the contact time for efficient degradation. FTIR analysis proved that control effluent showed specific peaks at $3464 \mathrm{~cm}^{-1}$ for $\mathrm{OH}$ stretching while in degraded product the peaks were obtained at $3387 \mathrm{~cm}^{-1}$ for N-H stretching. The disappearance of major peaks at the alkane groups further supports the degradation process. Phototoxicity studies conducted for authentic basic violet dye showed an inhibition of germination of Vigna radiata seedlings while complete germination was observed for the plants grown in the presence of degraded products which are less toxic or non-toxic to Vigna radiata.

\section{ACKNOWLEDGMENTS}

we like to thank kumaraguru college of technology for providing us support and laboratory facilities.

\section{REFERENCES}

1. Bidhendi, G R., Torabian, A., Ehsani, H. \& Razmkhah, N. 2007. Iran. J. Environ. Health. Sci. Eng. 4,29-36.

2. Childs R \& Bardsley W, 1975 .The steady-state kinetics of per-oxidase with 2,2'-azino-di-(3-ethylbenzthiazoline6-sulphonic acid) as chromogen, Biochem. J,145, 93-103.

3. Ge J \&Qu J,2003. Degradation of azo dye acid red B on manganese dioxide in the absence and presence of ultrasonic irradiation, J. Hazard. Mater, 100, 193-207.

4. Gould J P \& Groff K A,1987. Kinetics of ozonolysis of synthetic dyes, Ozone Sci. Eng, 9, 153. 
5. Harshad S L,2012. Enhanced biodegradation and detoxification of disperse azo dye Rubine GFL and textile industry effluent by defined fungal-bacterial consortium, International Biodeterioration \& Biodegradation, 72, 94107.

6. Kasuga K T, Hirose S, Aiba T, Takahashi S \&HirataniK,1998. Transport of monosaccharide through a liquid membrane mediated by lipophilic alkalic earth metal complex, Tetrahedron Lett, 39, 699-702.

7. Khelifi E, Bouallagui H, Touhami Y, Godon J, Hamdi M,2009. Enhancement of textile wastewater decolourization and biodegradation by isolated bacterial and fungal strains, Desalination and Water Treatment,2, 310-316.

8. Koyuncu I,2003. Direct filtration of procion dye bath wastewaters by nanofiltration membranes: Flux and removal characteristics, J. Chem. Technol. Biotechnol, 78, 1219.

9. Kuwahara M, Glenn J K, Morgan M A \& Gold M H,1984. Separation and characterisation of two extracellular $\mathrm{H}_{2} \mathrm{O}_{2}$ dependent oxidases ligninolytic cultures of Phanerochaete chrysosporium, FEBS letters, 169, $247-250$.

10. Lee D W, Won R \& Yup H K,2000. Removal of an organic dye from water using a predispersed solvent extraction, Separation Sci. Technol, 35, 1951-1962.

11. Mehrali S H, Alavi Moghaddam M R, Hashemi S H,2010 Removal of reactive blue 19 by adding polyaluminium chloride to sequencing batch reactor system, Iran. J. Environ. Health. Sci. Eng, 7 63-70.

12. Murphy J, Joseph G, Long L, Mitchell K \&Poje G V,2001 Hazard Investigation of Reactive Chemicals, Process Safety Progress, 20, 253-256

13. Nagda G K \&Ghole V S,2009. Biosorption of Congo red by hydrogen peroxide treated Tendu waste, Iran. J. Environ. Health. Sci. Eng, $6,195-200$.

14. Naimabadi A, Attar M H, Shahsavani A, 2009.Decolorization and biological degradation of azo dye reactive red 2 by anaerobic/aerobic sequential process, Iran. J. Environ. Health. Sci. Eng, 6, 67-72.

15. Pavko A, 2011.Fungal Decolourization and Degradation of Synthetic Dyes Some Chemical Engineering Aspects, Waste Water - Treatment and Reutilization, 65-88.

16. Qiu Y, Zheng Z, Zhou Z, Sheng G D,2009. Effectiveness and mechanisms of dye adsorption on a straw-based biochar, J Bioresource Tech,100,5348-5351

17. Qu Y, Shi S, Ma F, Yan B,2010. Decolorization of reactive dark blue K-R by the synergism of fungus and bacterium using response surface methodology, Bio-resource Technology, 101 , 8016-8023.

18. Rafi F, Fraeankalin W, Cerniglia C E,1990. Optimization of cultural condition for decolorization of textile effluent, Appl Environ Microbiol, $56,2146-2148$

19. Reddy $S \&$ Kotaiah $B, 2006$. Comparative evaluation of commercial and sewage sludge based activated carbons for the removal of textile dyes from aqueous solutions. Iran. J. Environ. Health. Sci. Eng, 3, 239-246.

20. Rezaee A, Ghaneian M. T, Khavanin A, Hashemian S J, Moussavi G H,2008. Photochemical oxidation of reactive blue 19 dye (RB19) in textile wastewater by UV/K2S2O8 process, Iran J Environ. Health. Sci. Eng, 5 , 95-100

21. Roy D, Valsaraj K T \&Kottai S A, 1992.Separation of organic dyes from wastewater by using colloidal gas aphrons, Separation Sci. Technol, 27, 573-88.

22. Snider E H \& Porter J J,1994. Ozone treatment of textile wastes, Journal of the Water Pollution Control Federation, $46,886$.

23. Su Y, Zhang Y, Wang J, Zhou J, Lu X, Lu H,.2009. Enhanced biodecolorization of azo dyes by co-immobilized quinone-reducing consortium and anthraquinone, Bioresource Technology, 100, 2982-2987.

24. Szygu1a A, Guibal E, Palaci'n M A, Ruiz M, Sastre A M,2009. Removal of an anionic dye (Acid Blue 92) by coagulation-flocculation using chitosan, J. Environ. Manage, 90, 2979-2986.

25. Tien M, Kirk T K, 1988.Lignin Peroxidase of Phanerochaete chrysosporium, Methods in Enzymology, 161, 238249

26. Van der Bruggen B, De Vreese I \&Vandecasteele C, 2001.Water reclamation in the textile industry: Nanofiltration of dye baths for wool dyeing, Indust. Eng. Chem. Res, 40, 3973-3978.

27. Vandevivere P C, Bianchi R, VerstraeteW,1998. Treatment and reuse of wastewater from the textile wetprocessing industry: review of emerging technologies, J. Chem. Technol. Biotechnol., 72, 289-302

28. Yu S, Liu M, Ma M, Qi M, Lü Z, Gao C,2010. Impacts of membrane properties on reactive dye removal from dye/salt mixtures by asymmetric cellulose acetate and composite polyamide nanofiltration membranes, J. Membr. Sci, 350, 83-91.

29. Zamora P, Pereira C M, Tiburtius E R L, Moraes S G, Rosa M A, Minussi R C, Duran N,2003. Decolorization of reactive dyes by immobilized laccase, Appl. Catal. B: Environ, $42,131-144$

\section{Authours Bibilography}

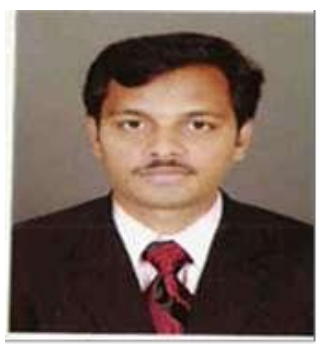

Mr. Manimaran, D.R. obtained his B. Tech. degree in Chemical Engineering from the University of Madras in the year 2002, M.E. degree in Chemical Engineering from Annamalai University, Chidambaram in the year 2004 and pursuing Ph.D. He has vast experience of over 12 years in Teaching and research. Industrial experience about 2 years related water treatment. His research interests include, Waste water treatment and bioremediation. He is an active life member in IIChE. He is active reviewer in some National and International Journals. Currently working as Co-Principal Investigator in R\&D project on Water Technology initiative funded by DST. 